\title{
Polimerik Bir Zincir Uzatıcının Geri Dönüştürülmüş Poli(Bütilen Tereftalat)'ın Özelliklerine Etkilerinin İncelenmesi
}

\section{Investigation of Effects of a Polymeric Chain Extender on the Properties of Recycled Poly (Butylene Terephthalate)}

\begin{abstract}
Başak Tuna $^{1 *}$
Geliş / Received: 24/07/2021

Revize / Revised: 27/10/2021

Kabul / Accepted: 28/10/2021

\section{ÖZ}

Poli(bütilen tereftalat) (PBT) günümüzde en fazla kullanılan poliesterlerdendir, ancak PBT atıkların geri dönüşüm kapsamında katma değerli ürünlere dönüşmesine yönelik girişimler hala sınırlıdır. PBT geri dönüşümünün en önemli zorluklarından birisi çoklu eriyik işleme döngüleri sırasındaki termal bozunma olup, polimerin molekül ağırlığ1 ve özelliklerinde kayıplara yol açmaktadır. Bu çalışmada geri dönüştürülmüş PBT (Gd. PBT) farklı yükleme oranındaki (\%ağ. 0.5, 1, 1.5) polimerik bir zincir uzatıcı (Joncryl ADR 4368) ile çift vidalı ekstrüderde harmanlanmıştır. Örneklerin reolojik, mekanik ve termal özellikleri farklı karakterizasyon yöntemleri ile incelenmiştir. Reolojik sonuçlar zincir uzatıcının eklenmesiyle kopan zincirlerin tekrar bağlanarak Gd. PBT'nin viskoelastik özelliklerinin geliştiğini göstermiştir. Zincir uzatıcının Gd. PBT’nin özelliklerine olan önemli etkisi çekme testi sonuçlarından da doğrulanmıştır. Zincir uzatıcı içeren örneklerin elastik modül ve çekme dayanımları artış gösterirken, kopmadaki uzama değerleri zincir dallanmasına bağlı olarak düşmüştür. Zincir uzatıcının örneklerin dallanmış yapısına etkisi düşük kristalinite değerlerinden de gözlemlenmiştir. Termogravimetrik analiz zincir uzatıcının Gd. PBT’nin termal bozunma sıcaklığını arttırdığını göstermiştir. Zincir uzatıcı içeren örneklerin özelliklerindeki iyileşme artan zincir uzatıcı konsantrasyonu ile daha belirgin olmuştur.
\end{abstract}

Anahtar Kelimeler- Poli(bütilen tereftalat), Geri Dönüşüm, Termal Bozunma, Zincir Uzatıcı, Ekstrüder

\begin{abstract}
Poly (butylene terephthalate) (PBT) is one of the most used polyesters today; however, the attempts to convert PBT wastes into value-added products are still limited in the recycling context. One of the major drawbacks of the PBT recycling is thermal degradation during multiple melt processing cycles that leads to deterioration in molecular weight and properties of the polymer. In this study, recycled PBT (rPBT) was compounded with a polymeric chain extender (Joncryl ADR 4368 ) at different loadings $(0.5,1,1.5 \mathrm{wt} \%)$ in a twin-screw extruder. The rheological, mechanical, and thermal properties of the samples were investigated using different characterization techniques. The rheological results showed that addition of chain extender improved the viscoelastic properties of rPBT due to recoupling of the broken chains. The profound effect of chain extender on upgrading properties of rPBT was also confirmed by tensile test results. The samples containing chain extender showed enhancement in elastic modulus and tensile strength, whereas the strain at break values decreased due to chain branching. The samples containing chain extender showed enhancement in elastic modulus and tensile strength, whereas the strain at break values decreased due to chain branching. The effect of chain extender on branched structure of the samples
\end{abstract}

1*Sorumlu yazar iletișim: basaktuna@ahievran.edu.tr (https://orcid.org/0000-0003-0366-8842)

Metalurji ve Malzeme Mühendisliği Bölümü, Kırşehir Ahi Evran Üniversitesi, Mühendislik-Mimarlık Fakültesi, Kırșehir. 
was also observed from the lower crystallinity values. Thermogravimetric analysis indicated that the chain extender increased thermal decomposition temperature of the PBT. The improvement in the properties of the samples containing chain extender became more significant with increase in chain extender concentration.

\section{Keywords- Poly(butylene terephthalate), Recycling, Thermal Degradation, Chain Extender, Extruder}

\section{GIiRiș}

Plastikler, seramik ve metaller gibi diğer malzemeler ile karşılaştırıldığında kolay işlenebilirliği, hafifliği, korozyona karşı direnci ve düşük maliyeti gibi özelliklerinden dolayı hayatımızın vazgeçilmez bir parçası olmuştur [1]. Özellikle son 50 yılda plastik üretimi dünya çapında büyük artış göstererek önemli bir endüstri ve ekonomik pazar halini almıştır [2]. Fakat plastiklerin petrol türevli malzemeler olması ve doğada uzun süre bozulmadan kalabilmesi çevresel ve sosyo-ekonomik sorunları da beraberinde getirmiştir. Bu aşamada geri dönüşüm, hem üretimde doğal kaynaklara bağlılığı azaltarak hem de atıkların yeniden değerlendirilmesini sağlayarak çevresel sürdürebilirlik ve döngüsel ekonomiye önemli katkılar sunmaktadır [3].

Poli(bütilen tereftalat) (PBT), tereftalik asit veya dimetil tereftalat ile 1,4-bütandiolün kondenzasyon (basamaklı) polimerizasyonu sonucunda sentezlenen poliesterler grubuna ait önemli bir mühendislik termoplastiğidir. Kolay işlenebilirliği, yüksek mekanik ve termal özellikleri, elektriksel yalıtkanlığı ve çözücülere karşı dayanımından dolayı günümüzde birçok alanda yaygın olarak kullanılmaktadır. Elektrik düğmeleri, prizler, fiber optik kablo kılıfları, sigorta panoları, arabaların iç aksesuarları, oyuncaklar, mutfak ve spor eşyalarının üretiminde ana malzeme olarak PBT'den faydalanılmaktadır [4-6]. Ancak günümüzde bu ürünlerin tüketiciler tarafından kullanım sürelerinin kısalması, oluşan atıkların geri dönüştürülüp yeniden değerlendirilmesini zorunlu kılmaktadır [7].

Plastik atıkların geri dönüşümünü kimyasal ve mekanik olmak üzere iki temel proses teşkil etmektedir. [8]. Mekanik geri dönüşüm; ekonomik, basit ve çevre dostu bir yöntem olması, endüstriyel üretim yöntemlerine uygunluğu gibi nedenlerden dolayı daha fazla tercih edilmekte ve endüstride de yaygın olarak kullanılmaktadır. Bütün bu avantajlarının yanında plastiklerin mekanik geri dönüşümü önündeki en büyük engel ekstrüzyon ve enjeksiyonlu kalıplama ile tekrarlanan termal ve mekanik yeniden işleme döngüleriyle bozulmaya uğrayarak polimer zincirlerinin kopmasıdır. Yapıda meydana gelen bu bozulmalar polimerin moleküler ağırlığında dolayısıyla da eriyik gücünde düşüşlere neden olmaktadır. Moleküler ağırlıktaki düşüş mekanik, termal ve reolojik özellikleri zayıflatarak polimer performansını olumsuz etkilemekte olup, bu probleme çözüm geliştirmek önemli bir gereklilik halini almıştı [9]. Passalacqua ve arkadaşları [10] tarafından yapılan bir çalışmada PBT' nin ekstrüzyon ve enjeksiyonlu kalıplamada kullanılan proses sıcaklıklarına yakın olarak $240-280^{\circ} \mathrm{C}$ aralığındaki termal bozunma mekanizması incelenmiştir. Çalışmadan elde edilen veriler PBT'de termal bozunmanın ester bağlarının kopmasıyla gerçekleştiğini, bozunma ürünleri olarak ise bütadien ve karboksil zincir sonu gruplarına sahip halkalı bileşiklerin meydana geldiğini göstermiştir.

PBT gibi kondenzasyon polimerizasyonu ile sentezlenen poliesterler grubunun diğer üyelerinden poli(etilen tereftalat) (PET) ve poli(laktik asit)'in (PLA) moleküler ağırlı̆̆ını artırmak için katı hal polimerizasyon yöntemi yaygın olarak kullanılmaktadır. Bu yöntemde polimer granülleri vakum ve azot atmosferi altında erime noktasına yakın bir sıcaklıkta 20-50 saat arasında isıtılır. Kompleks ve yüksek maliyetli reaktör sistemlerinde uzun süre ve özel koşullar altında (vakum ve inert gaz) gerçekleşmesi; katı hal polimerizasyonun yerini alabilecek daha basit, ekonomik ve hızlı bir yöntem geliştirilmesine yönelik araştırmalara yol açmıştır. Bu aşamada, iki veya daha fazla fonksiyonel gruba sahip kimyasal bileşikler olan zincir uzatıcıların kullanılması katı hal polimerizasyon yöntemine önemli bir alternatif olmaktadır [11]. Bu yöntemde, zincir uzatıcılar bozulmaya uğramış kondenzasyon polimerlerinin hidroksil (-OH) veya karboksil (-COOH) fonksiyonel son gruplarını bir köprü vazifesi görerek birbirine bağlar ve moleküler ağırlığın artmasını sağlarlar. Zincir uzatımı reaksiyonları genellikle tek veya çift vidalı ekstrüderlerde gerçekleştirildiğinden reaktif ekstrüzyon yöntemi olarak adlandırılmaktadır $[12,13]$. Bu yöntem geri dönüştürülmüş PET (Gd. PET) ve geri dönüştürülmüş PLA'nın (Gd. PLA) molekül ağırlığının arttırılması ve özelliklerinin iyileştirilmesinde uygulanmış ve başarılı sonuçlar elde edilmiştir [14-26].

Xiao ve arkadaşları [18] epoksi bir zincir uzatıcının Gd. PET' in özelliklerine olan etkisini incelemiştir. Reolojik sonuçlar Gd. PET' in viskozitesinin zincir uzatıcı ile reaktif ekstrüzyonu sonrası arttığını göstermiştir. Polimer yapısında meydana gelen zincir dallanmalarına bağlı olarak zincir uzatıcı içeren örneklerin erime ve kristallenme sıcaklıklarında düşüş meydana gelmiştir. Bir diğer çalışmada Tavares ve arkadaşları [19] epoksi bir zincir uzatıcının Gd.PET ve işlem görmemiş PET' in molekül ağırlığına etkilerini incelemiştir. Zincir uzatıcı her 
iki PET türünün molekül ağırlığını arttırmış ancak bu artış işlem görmemiş PET ile karşılaştıııldığında Gd. PET için \%10 oranında daha fazla olmuştur. Zincir uzatıcı konsantrasyonu iki katına çıkarıldığında (\%1.5'den \%3'e) Gd. PET' in molekül ağırlığında \%20 artış gözlemlenmiştir. Haralabakopoulos ve arkadaşları [20] araştırmalarında Gd. PET' in epoksi bir zincir uzatıcıyla laboratuvar ölçekli karıştırıcıda zincir uzatımı reaksiyonunu incelemiştir. Zincir uzatıcı içeren örneklerin intrinsik viskozitelerinin $(0.68-0.75 \mathrm{dL} / \mathrm{g})$ işlem görmemiş (geri dönüştürülmemiş) PET $(0.74 \mathrm{dL} / \mathrm{g})$ ile oldukça yakın değerlerde, Gd. PET' ten $(0.55 \mathrm{dL} / \mathrm{g})$ ise yüksek olduğu rapor edilmiştir. Incarnato ve arkadaşları [21] Gd. PET' in özelliklerini piromellitik dianhidrit (PMDA) zincir uzatıcısıyla geliştirmeye çalışmışlardır. Reolojik sonuçlar; \%0.5-0.75 PMDA konsantrasyonunda Gd. PET' in viskoelastik özelliklerinin arttığını göstermiştir. Awaja ve arkadaşları [22] tarafından yapılan çalışmada \% 0.3 ve üzerindeki PMDA konsantrasyonlarının Gd. PET' in intrinsik viskozitesini arttırdığ 1 ve karboksil son grubunda azalmayı sağladığını belirtilmiştir. Bunun yanı sıra elde edilen ürünlerde, zincir dallanması ve jel oluşumu gözlemlenmiştir. Daver ve arkadaşları [23] tarafından yürütülen benzer bir çalışmada araştırmacılar \%0.25 PMDA konsantrasyonu üzerinde Gd. PET' te zincir dallanması meydana geldiğini gözlemlemişlerdir.

Poliesterler grubunun bir diğer üyesi olan PLA ile yapılan bir çalışmada, Tuna ve Ozkoc [24] Gd. PLA' nın özelliklerini diizosiyanat ve epoksi zincir uzatıcılarını kullanarak geliştirmeye çalışmışlardır. Dikey kuvvet ölçümleriyle elde edilen reoloji sonuçları, PLA'nın ekstrüderde işlenirken zamanla termal bozulmaya uğrayarak moleküler ağırlığının azaldığını ve dikey kuvvette düşüşlerin gerçekleştiğini göstermiş̧tir. Her iki zincir uzatıcı türünün de ekstrüdere eklenmelerinden sonra PLA ile reaksiyona girerek dikey kuvveti arttırdıkları gözlemlenmiştir. İntrinsik viskozite, mekanik ve diğer reolojik testler de zincir uzatıcıların moleküler ağırlı̆̆ arttırarak Gd. PLA'nın özelliklerini geliştirdiğini göstermiş̧tir. Beltran ve arkadaşları [25] tarafından yürütülen araştırmada Gd. PLA' nın epoksi zincir uzatıcı ve peroksit (dikümil peroksit) ile reaksiyona girerek moleküler ağırlığının arttırılması amaçlanmıştır. Jel geçirgenlik kromatografisi (GPC), intrinsik viskozite, termal ve mekanik test sonuçları ışığında PLA' nın geri dönüştürülmesiyle moleküler ağırllı̆ğnda ve özelliklerinde azalma; zincir uzatıcı ve peroksit bileşiklerinin eklenmesiyle polimerin moleküler ağırlığı ve termal dayanımında artışlar olduğu gözlemlenmiştir. Bir başka araştırmada Casate de Andrade ve arkadaşları [26] Gd. PLA’ ya \%0.6 oranında epoksi zincir uzatıcı eklemişlerdir. GPC ve eriyik akış indeksi (MFI) sonuçları zincir uzatıcı içeren Gd. PLA örneklerin moleküler ağırlığında artış olduğunu göstermiştir. Buna bağlı olarak termal dayanımın geliştiği, termogravimetrik analiz (TGA) sonuçlarından termal bozunma sıcaklığındaki $\left(\mathrm{T}_{\mathrm{d}}\right)$ yükselme ile açıklanmıştır.

Literatürdeki çalışmalarda, zincir uzatıcılardan işlem görmemiş PBT’nin mevcut özelliklerini geliştirmek ve köpük üretimi gibi farklı alanlarda kullanımlarını sağlamak amacıyla faydalanılmı̧ olup; PBT'nin geri dönüşümü sonrası özelliklerinin iyileştirilmesi araştırılmamıştır. Standau ve arkadaşları [27] tarafından yürütülen çalışmada epoksi zincir uzatıcı, PBT'nin reolojik özelliklerini geliştirmesi ve köpük olarak üretiminin araştırılmasında kullanılmıştır. Sonuçlar zincir uzatıcının PBT’nin viskozitesini yükselttiği, yüksek genleşme, homojen ve gelişmiş hücre morfolojisi ile köpük oluşumunu arttırdığını göstermiştir. Termal özellikler incelendiğinde; zincir uzatıcı erime sıcaklığını değiştirmezken, örneklerin kristal yüzdesi zincir uzatıcı içeriğindeki artış ile azalma eğilimi göstermiştir. Bunun yanı sıra reolojik analizlerden \%0.5-2 zincir uzatıcı konsantrasyonlarında örneklerin yapısında zincir dallanmaları meydana geldiği sonucuna varılmıştır. Başka bir çalışmada, Villalobos ve arkadaşları [13] işlem görmemiş PBT granüllerini farklı konsantrasyonlardaki epoksi zincir uzatıcı ile çift vidalı ekstrüderde harmanlamıştır. Reolojik sonuçlardan zincir uzatıcı konsantrasyonu ile örneklerin viskozitesinin artış gösterdiği ve buna bağlı olarak kayma incelmesi davranışı sergiledikleri saptanmıştır.

Bu çalışmada Gd. PBT' nin özelliklerinin epoksi fonksiyonel grubuna sahip bir zincir uzatıcı kullanılarak iyileştirilmesi amaçlanmıştır. Farklı yükleme oranlarındaki zincir uzatıcının Gd. PBT’nin reolojik, mekanik ve termal özelliklerine etkileri incelenmiştir. 


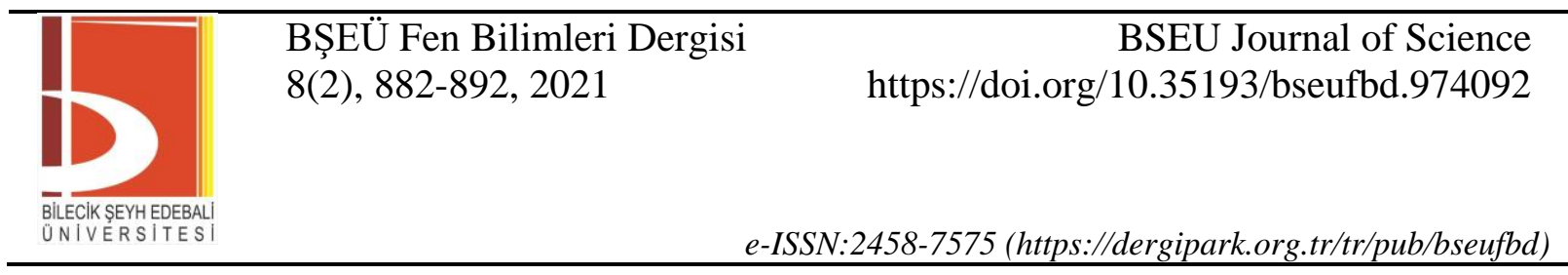

\section{MALZEME VE METOD}

Deneysel çalışmada kullanılan PBT granül halinde, eriyik hacim akış hızı $45 \mathrm{~cm}^{3} / 10 \mathrm{dk}\left(250{ }^{\circ} \mathrm{C}\right)$ ve yoğunluğu $1.3 \mathrm{~g} / \mathrm{cm}^{3}$ olan BASF firmasından temin edilen Ultradur B2550'dir. Zincir uzatıcı BASF tarafindan üretilmekte olup, ticari ismi Joncryl ADR 4368 olan çoklu epoksi reaktif gruplarına sahip stiren glisidil akrilat kopolimeridir (EPO). Bu zincir uzatıcının kimyasal yapısı Tablo 1'de gösterilmekte olup; molekül ağırlığı 6800 $\mathrm{g} / \mathrm{mol}$, yoğunluğu $1080 \mathrm{~kg} / \mathrm{m}^{3}$ ve camsı geçiş sıcaklığ $\left(\mathrm{T}_{\mathrm{g}}\right) 54^{\circ} \mathrm{C}$ 'dir.

Tablo 1. Çalışmada kullanılan zincir uzatıcının kimyasal yapısı

Zincir uzatıcı Kimyasal yapı

PBT'nin ekstrüzyonu sırasında oluşan termo-mekanik bozunmaları simüle etmek amacıyla, işlem görmemiş PBT granülleri, Baker Perkins marka APV MP19TC ( $/ \mathrm{D}=28)$ çift vidalı ekstrüderde bir kez işlenmiş ve elde edilen ürün Gd. PBT olarak kullanılmıştır. Bu ekstrüzyon işlemi $150 \mathrm{rpm}$ vida hızı ve besleme bölgesinden çıkışa doğru 225-255-260-265-265 ${ }^{\circ} \mathrm{C}$ kovan sıcaklık profili uygulanarak gerçekleştirilmiş̧tir. Ekstrüderden filament şeklinde alınan ürün su banyosunda soğutularak kesme ünitesinden geçirilip granül haline getirilmiş ve Gd. PBT elde edilmiştir. Daha sonra Gd. PBT granülleri ile \%0.5, 1 ve 1.5 oranlarında zincir uzatıcı iki ayrı besleme ünitesinden eş zamanlı olarak vida kovanına verilerek önceki ekstrüzyon işleminde kullanılan vida hızı ve kovan sıcaklı̆̆ında harmanlanmıştır. Her ekstrüzyon işleminden önce polimer ve zincir uzatıcı vakum altında $80^{\circ} \mathrm{C}$ 'de 12 saat kurutularak ekstrüzyon sürecinde meydana gelebilecek olası bir hidrolitik bozunma engellenmeye çalışılmıştır.

Fourier dönüşümlü kızıl ötesi spektroskopisi (FTIR) azaltılmış toplam yansıma (ATR) modunda, 3000$600 \mathrm{~cm}^{-1}$ dalga sayısı aralığında Thermo Scientific Nicolet iS-50 FTIR marka cihaz kullanılarak gerçekleştirilmiştir.

Reolojik analizler paralel plaka ölçüm sistemine sahip Anton Paar Physica MCR 501 rotasyonel reometre kullanılarak $230{ }^{\circ} \mathrm{C}^{\prime}$ de gerçekleştirilmiş̧tir. Testlerde kullanılan örnekler Moore marka sıcak pres kullanılarak 25 mm çapında ve $1 \mathrm{~mm}$ kalınlığında diskler haline getirilmiştir. Bu işlem sırasında sıcaklık $230{ }^{\circ} \mathrm{C}$, basınç $20 \mathrm{MPa}$ ve süre 4 dakikadır. Genlik tarama testi ile tespit edilen doğrusal viskoelastik bölge içerisindeki $\% 0.5$ gerinim değeri kullanılarak numunelerin $0.1-100 \mathrm{~Hz}$ frekans aralığındaki viskoelastik davranışları incelenmiştir. Numunelerin kompleks viskozite $\left(\eta^{*}\right)$ ve depolama modülünün $\left(\mathrm{G}^{\prime}\right)$ frekansa göre değişimleri kaydedilmiştir.

Mekanik özellikler çekme testi ile belirlenmiş olup; test örnekleri ASTM D638 standartlarına göre, Moore marka sıcak pres ile $230^{\circ} \mathrm{C}$ 'de, $20 \mathrm{MPa}$ basınçta, 4 dakika süresinde hazırlanmıştır. Testler, Instron 5564 marka çekme test cihazı kullanılarak oda sıcaklığında $5 \mathrm{~mm} /$ dakika çekme hızında gerçekleştirilmiştir. Her örnek grubu için en az 5 paralel test yapılıp ortalamaları alınarak; elastik modül, çekme dayanımı ve kopmadaki uzama değerleri elde edilmiştir.

Örneklerin termal özellikleri diferansiyel taramalı kalorimetri (DSC) ve TGA testleri ile belirlenmiştir. DSC analizleri TA Instruments Discovery DSC kullanılarak süpürücü gaz azot ortamında gerçekleştirilmiştir. Örnekler $10 \mathrm{mg}$ 'ı geçmeyecek şekilde alüminyum krozelere yerleştirilerek $10^{\circ} \mathrm{C} / \mathrm{dk}$ sabit hızda 1sıtma ve soğutma $\left(25^{\circ} \mathrm{C} \rightarrow 250^{\circ} \mathrm{C} \rightarrow 25^{\circ} \mathrm{C}\right)$ işlemlerine tabi tutulmuştur. Elde edilen termogramlardan; camsı geçiş sıcaklığ $1\left(\mathrm{~T}_{\mathrm{g}}\right)$, erime sıcaklığ $1\left(T_{m}\right)$, kristallenme sıcaklığ $1\left(T_{c}\right)$ ve erime entalpisi $\left(\Delta H_{m}\right)$ elde edilmiştir. Örneklerin toplam kristal yüzdesi $\left(\chi_{c}\right)$; Meng ve Qu'nin [6] çalışmaları referans alınarak Denklem 1'e göre hesaplanmışıtır. Denklemde; $\omega$ örnekteki PBT’nin ağırlıkça oranını ve $\Delta \mathrm{H}_{\mathrm{m}}^{\mathrm{o}}$ ise $\% 100$ kristalin PBT'nin erime entalpisini göstermektedir. $\Delta \mathrm{H}_{\mathrm{m}}^{\mathrm{o}}$ literatürden elde edilen veriler temelinde $145 \mathrm{~J} / \mathrm{g}$ değeri olarak alınmıştır [6, 28]. 


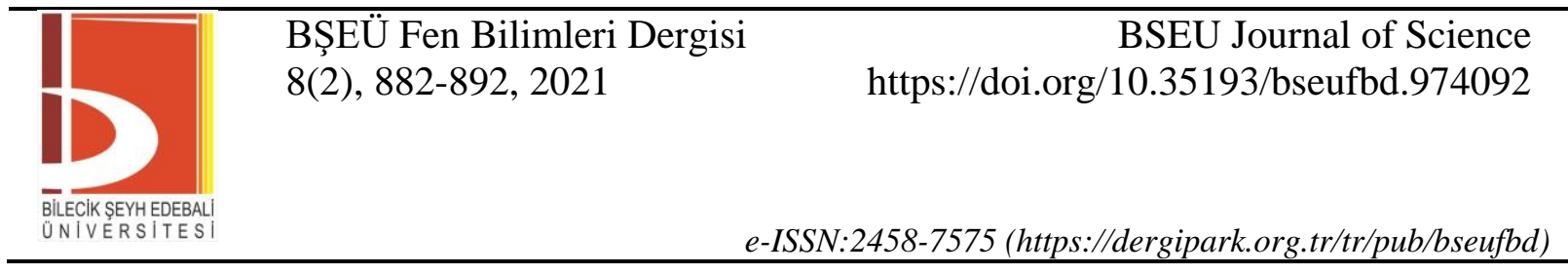

$$
\chi_{c}=\frac{\Delta H_{m}}{\omega \Delta H_{m}^{o}}
$$

TGA testleri TA Instruments Discovery DSC kullanılarak azot ortamında gerçekleştirilmiştir. Yaklaşık 8 mg ağırlığındaki örnekler $25-650^{\circ} \mathrm{C}$ sıcaklık aralığında ve $10^{\circ} \mathrm{C} / \mathrm{dk}$ ssıtma hızında analiz edilerek örneklerin $\% 5$ kütle kaybına karşılık gelen $T_{d}$ değerleri kaydedilmiştir.

\section{BULGULAR VE TARTIŞMA}

Şekil 1'de örneklerin FTIR spektrumları gösterilmiştir. Literatürde epoksi zincir uzatıcıların poliesterlerin karboksilik asit ve hidroksil son grupları ile reaksiyona girebildiği, ancak karboksilik asit son grupları ile reaksiyona daha yatkın olduğu belirtilmiştir [29-32]. Sonuçlar incelendiğinde en yüksek zincir uzatıcı konsantrasyonuna sahip Gd. PBT/1.5 EPO örneğinde karbonil grubuna ait $1711 \mathrm{~cm}^{-1}$ ' deki pikin $(\mathrm{C}=\mathrm{O}$ gerilmesi) yüksekliğinde azalma, diğer örneklerin spektrumlarında ise değişimin olmadığı görülmektedir. Bu bulgu, termal bozunma ve düşük zincir uzatıcı konsantrasyonlarının örneklerin FTIR spektrumunda değişimlerin izlenmesine olanak vermemesi şeklinde yorumlanabilir [33,34]. Gd. PBT/1.5 EPO örneğinde gözlemlenen bu değişim, Şekil 2'de gösterildiği üzere karboksilik asit son gruplarının zincir uzatıcının epoksi grupları ile reaksiyona girerek, örnekteki içeriğinin azalmasından kaynaklanmaktadır. Bu sonuç literatürdeki verileri destekler nitelikte olup, çalışmada kullanılan zincir uzatııının (EPO) termal bozunmaya uğramış poliesterlerin karboksilik asit son grupları ile reaksiyonu için uygun bir zincir uzatıcı türü olduğunu göstermektedir [30-32].

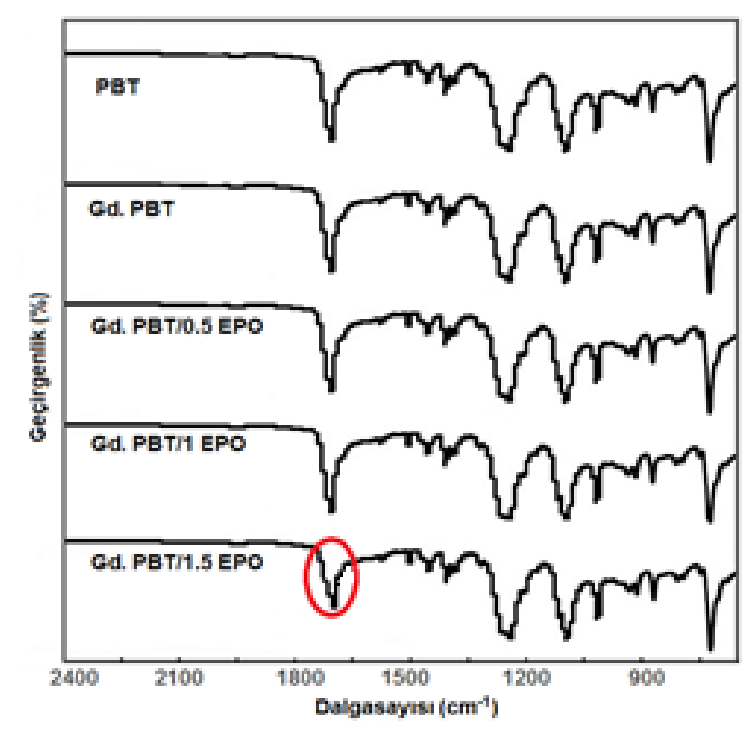

Şekil 1. Örneklerin FTIR spektrumları<smiles>[R]C(O)COC(=O)CCCCCC(=O)O</smiles>

Şekil 2. PBT ve zincir uzatıcı arasında gerçekleşen reaksiyon mekanizması

Reolojik özellikler, polimerlerin moleküler yapısı ile doğrudan ilişkili olup, ekstrüzyondaki termomekanik etkiler ve zincir uzatımı/dallanmaları sonucu örneklerin yapısında meydana gelen değişimlerin belirlenmesinde önemli bir araçtır. Bu bağlamda Şekil 3 örneklerin frekans taraması boyunca kompleks viskozitelerindeki değişimleri göstermektedir. PBT mekanik geri dönüşüm sürecinde ekstrüderde işlenmesiyle termal bozunmaya uğrayarak polimer zincirlerinde kopmalar meydana gelmekte, zincirler bütadien ve karboksil zincir sonu gruplarına ayrılmaktadır [10,35]. İşlem görmemiş PBT’nin $1 \mathrm{~Hz}$ frekansındaki kompleks viskozitesinin 2171 Pa.s’den geri dönüştürülmesi ile 1554 Pa.s değerine düşmesi bu bilgiye dayanarak açıklanabilir. 


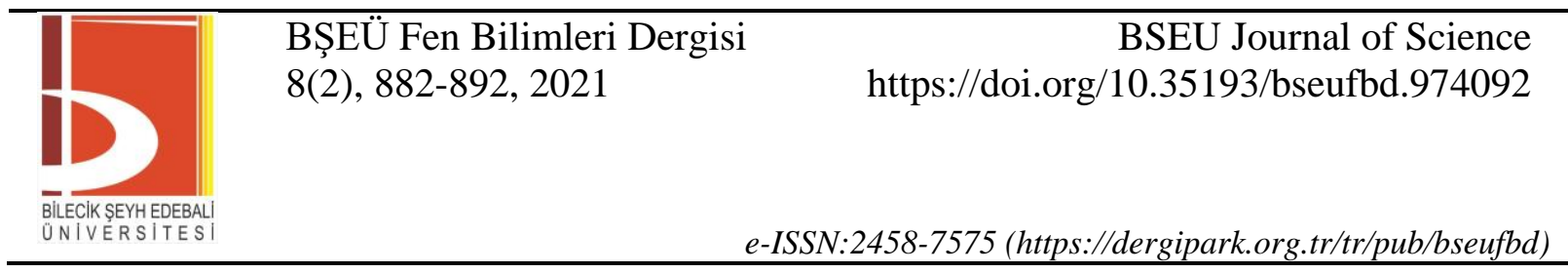

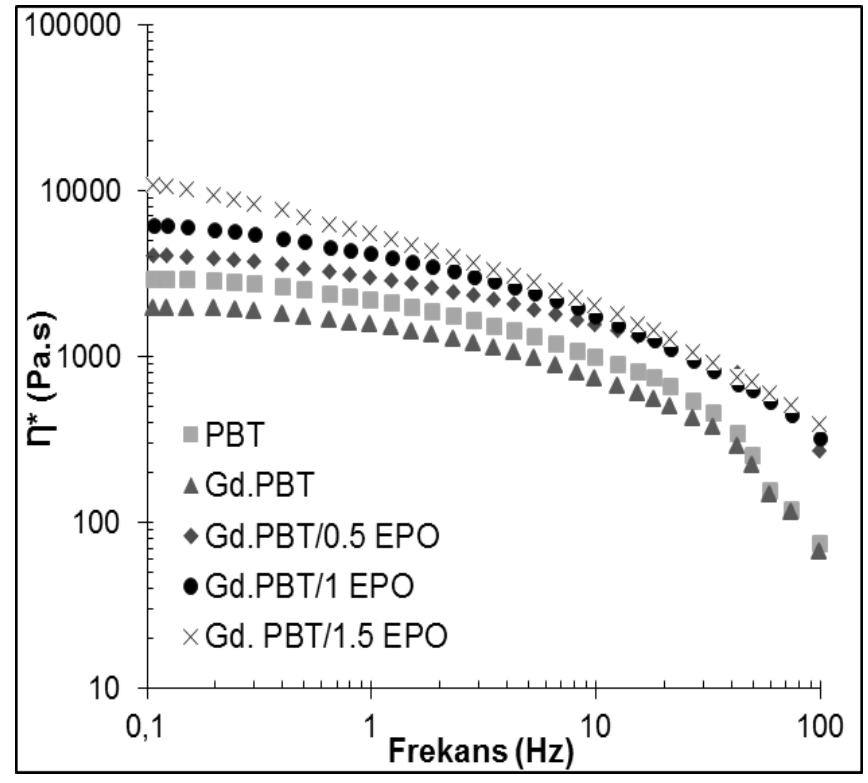

Şekil 3. Örneklerin frekans taraması testindeki kompleks viskozite değişimleri

Şekil 3'te zincir uzatıcı konsantrasyonu ile örneklerin viskozitelerinin doğru orantılı olarak değiştiği gözlemlenmektedir. $1 \mathrm{~Hz}$ frekansında \% 0.5, 1 ve 1.5 konsantrasyonları için örneklerde sırasıyla 3031 Pa.s, 4149 Pa.s ve 5533 Pa.s değerleri elde edilmiştir. Konsantrasyondaki artışa bağlı olarak zincir uzatıcı ekstrüzyon sırasında daha fazla sayıda polimer zincirini birbirine bağlamış ve viskoziteyi arttırmışıı. Burada dikkat çekici bir diğer sonuç zincir uzatılmış örneklerin viskozitelerinin, özellikle düşük frekanslarda daha belirgin olmak üzere işlenmemiş PBT' den daha yüksek değerler göstermesidir. Zincir uzatımının yanı sıra polimer zincirlerinde meydana gelen dallanmalar kompleks viskozitedeki bu önemli artışın sebebi olarak açıklanabilir. Khankrua ve arkadaşları [36] yaptıkları çalışmada polimer zincirlerinde meydana gelen dallanmaların sebebini zincir uzatıcının çoklu epoksi reaktif grupları ile ilişkilendirmiştir. Bu sonuçlara ek olarak örneklerin kompleks viskozitelerinin frekans taraması boyunca azalarak tipik kayma incelmesi davranışı gösterdiği görülmektedir. Bu davranış özellikle yüksek zincir uzatıcı konsantrasyonundaki örnekte (Gd. PBT/1.5 EPO) daha belirgin olup yüksek molekül ağırlık ve zincir dallanmalarıyla ilgilidir [32,37].

Depolama modülü polimerlerin eriyik elastisitesinin bir göstergesi olarak göz önünde bulundurulduğunda, zincir uzatıcının eklenmesiyle örneklerin moleküler yapısındaki değişimler Şekil 4'ten yararlanılarak yorumlanabilir. Buna göre, zincir uzatıcının artan konsanstrasyonu ile örneklerin depolama modülü değerleri özellikle düşük frekanslarda daha belirgin olmak üzere artış göstermiştir. Örneğin $1 \mathrm{~Hz}$ frekansta $\% 0.5$, 1 ve 1.5 konsantrasyonları için örneklerde sırasıyla $4643 \mathrm{~Pa}, 10640 \mathrm{~Pa}$ ve $20770 \mathrm{~Pa}$ değerleri elde edilmiştir. Gd. PBT'nin verileri incelendiğinde ise ekstrüzyonda yüksek sıcaklık ve kayma gerilimlerine maruz kalan polimerin yapısında meydana gelen bozunmanın etkileri açıkça görülmektedir. $1 \mathrm{~Hz}$ frekansta işlem görmemiş PBT için depolama modülü 3527 Pa iken, Gd. PBT 1198 Pa değerini göstermiş̧tir.

Genel anlamda bakıldığında frekans taraması testlerinde örneklerin kompleks viskozite ve depolama modülü eğrilerinin yüksek frekanslara doğru birbirine yaklaşı̆ı̆ı görülmektedir. Örneklerin gösterdiği bu davranış yapıdaki fiziksel bağların artan frekans ile zarar görmesi şeklinde yorumlanabilir. 


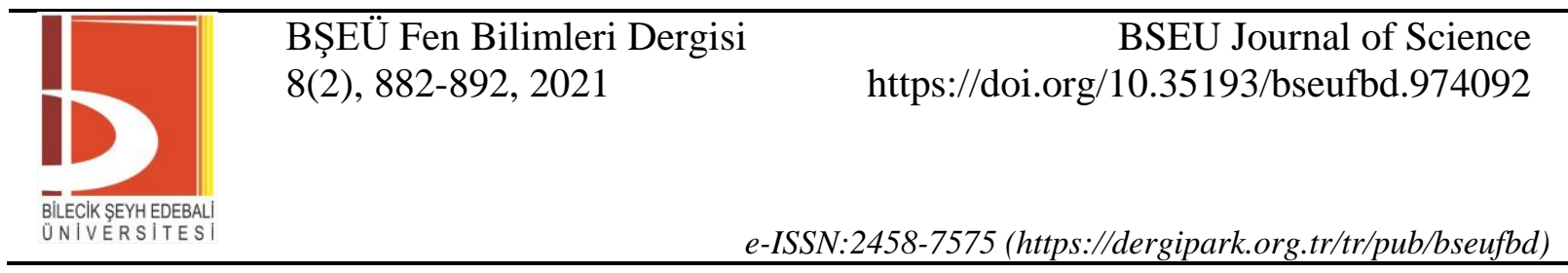

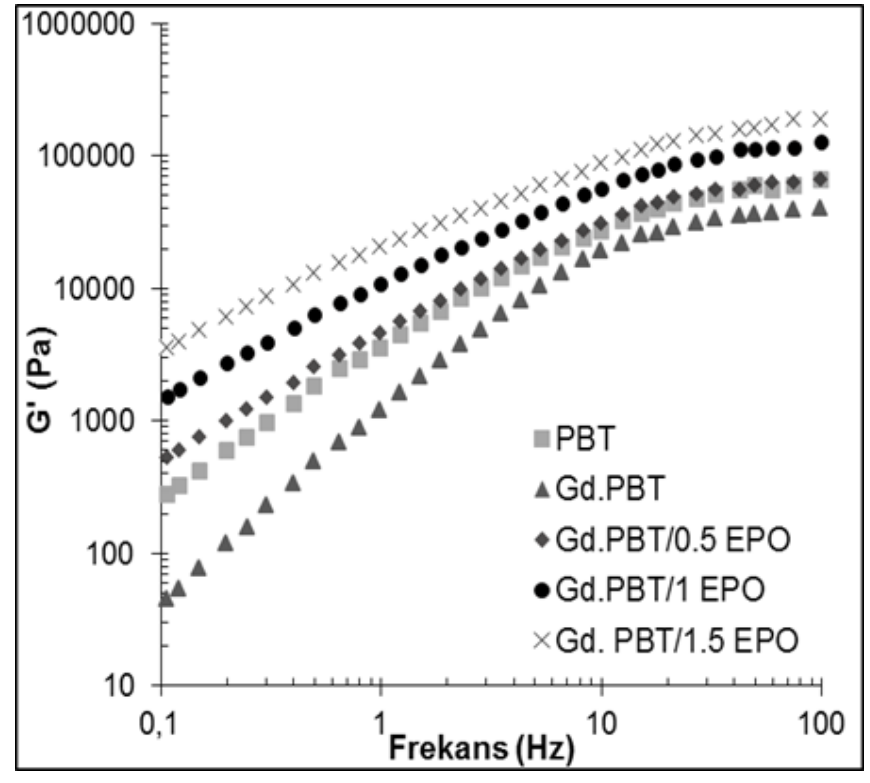

Şekil 4. Örneklerin frekans taraması testindeki depolama modülü değişimleri

Polimerlerin moleküler ağırlığının mekanik özelliklere önemli etkisi olup, çalışmada örneklerin termal bozunma ve zincir uzaması sonucunda yapısındaki değişiklerin izlenmesinde önemli bir araçtır. Bu bağlamda, Tablo 2'de örneklerin çekme testinden elde edilen elastik modül, çekme dayanımı ve kopmadaki uzama değerleri sunulmaktadır. Gd. PBT'nin ekstrüzyon sırasında termal bozunma etkisi ile zincirlerinde kopmalar meydana gelerek moleküler ağırlığı azalmış, buna bağlı olarak örnekler içerisindeki en düşük elastik modül ve çekme gerilimi değerlerini göstermiştir. PBT'nin geri dönüştürülmesiyle, işlenmemiş PBT' ye kıyasla elastik modülünde $\% 26$, çekme geriliminde ise $\% 10$ oranında azalma meydana gelmiştir. Gd. PBT ile karşılaştırıldığında zincir uzatıcı içeren örneklerin özellikle yüksek konsantrasyon oranlarında molekül ağırlığındaki gelişmeye bağlı olarak elastik modül ve çekme dayanımı değerleri de artmıştır. En yüksek zincir uzatıcı konsantrasyonuna sahip örnek olan Gd. PBT/1.5 EPO' nin, Gd. PBT’ ye göre elastik modülünde \% 33 çekme geriliminde ise \% 26 oranındaki yükseliş bunun bir göstergesidir. Örneklerin kopmadaki uzama verileri incelendiğinde, Gd. PBT'nin en yüksek değere sahip olduğu görülmektedir. Bu sonuç, termal bozunma etkisi ile kopan ve kısalan zincirlerin daha kolay hareket edebilmesine ve buna bağlı olarak test sırasında daha fazla uzama gösterebilmesine bağlanabilir. Diğer taraftan zincir uzatıcı polimer zincirlerinde dallanmalara yol açarak uzama sırasında polimer zincirlerinin yönelimlerini kısıtlamış ve örneklerin uzama değerlerini düşürmüştür [38].

Tablo 2. Örneklerin mekanik özellikleri

\begin{tabular}{lccc}
\hline Örnek & $\begin{array}{c}\text { Elastik modül } \\
(\mathbf{M P a})\end{array}$ & $\begin{array}{c}\text { Çekme dayanımı } \\
(\mathbf{M P a})\end{array}$ & $\begin{array}{c}\text { Kopmadaki uzama } \\
(\boldsymbol{\%})\end{array}$ \\
\hline PBT & $2168 \pm 49$ & $76 \pm 2$ & $36 \pm 2$ \\
Gd. PBT & $1720 \pm 45$ & $69 \pm 2$ & $39 \pm 2$ \\
Gd. PBT/0.5 EPO & $2184 \pm 33$ & $77 \pm 1$ & $22 \pm 1$ \\
Gd. PBT/1 EPO & $2217 \pm 23$ & $86 \pm 1$ & $20 \pm 2$ \\
Gd. PBT/1.5 EPO & $2301 \pm 19$ & $87 \pm 1$ & $18 \pm 2$ \\
\hline
\end{tabular}

Çalışmanın bu bölümünde termal analiz kapsamında DSC ve TGA testleri kullanılarak örneklerin erime, kristallenme ve termal bozunma davranışlarının anlaşılarak geri dönüşüm ve zincir uzatıcının PBT'nin termal özelliklerine etkilerinin belirlenmesi sağlanmıştır. Örneklerin DSC analiz sonuçları Tablo 3 ve Şekil 5'te gösterilmiştir. Veriler incelendiğinde örneklerin camsı geçiş sıcaklığı ve erime sıcaklıklarında değişimin oldukça az olduğu, buna karşın toplam kristal yüzdesi ve kristallenme sıcaklıklarında farkların meydana geldiği görülmektedir. En yüksek zincir uzatıcı konsantrasyonu içeren örnek ile karşılaştırıldığında (Gd. PBT/1.5 EPO), Gd. PBT'nin toplam kristal yüzdesi \% 40’tan \% 27 oranına düşmüştür. Zincir uzatıcı; polimerin daha zor kristallenme göstermesine, buna bağlı olarak örneklerin kristallenme sıcaklığında artışa ve kristal yüzdesinde azalışa sebep olmuştur. Bu davranış zincir uzatıcının yapısındaki büyük benzen halkalarının neden olduğu sterik engel veya zincir uzatıcının çoklu epoksi gruplarının polimer zincirlerinde dallanmalara yol açması ile 
açıklanabilir. Bu etkiler neticesinde polimer zincirlerinin hareket kabiliyeti azalarak kristal yapı oluşturmaları zorlaşır. Buna karşılık Gd. PBT'nin yüksek kristallenme göstermesinin sebebi, termal bozunma sonucunda zincirlerinin kopması ve kısa zincirlerin daha kolay hareket ederek kristallenebilmesidir.

Tablo 3. Örneklerin termal özellikleri

\begin{tabular}{lccccc}
\hline Örnek & $\mathbf{T}_{\mathbf{g}}\left({ }^{\mathbf{}} \mathbf{C}\right)$ & $\mathbf{T}_{\mathbf{m}}\left({ }^{\mathbf{}} \mathbf{C}\right)$ & $\mathbf{T}_{\mathbf{c}}\left({ }^{\mathbf{}} \mathbf{C}\right)$ & $\mathbf{X}_{\mathbf{c}}(\boldsymbol{\%})$ & $\mathbf{T}_{\mathbf{d}}\left({ }^{\mathbf{}} \mathbf{C}\right)$ \\
\hline PBT & 52 & 219 & 186 & 37 & 421 \\
Gd. PBT & 53 & 221 & 182 & 40 & 412 \\
Gd. PBT/0.5 EPO & 52 & 220 & 187 & 31 & 437 \\
Gd. PBT/1 EPO & 54 & 221 & 188 & 29 & 442 \\
Gd. PBT/1.5 EPO & 54 & 222 & 188 & 27 & 444 \\
\hline
\end{tabular}

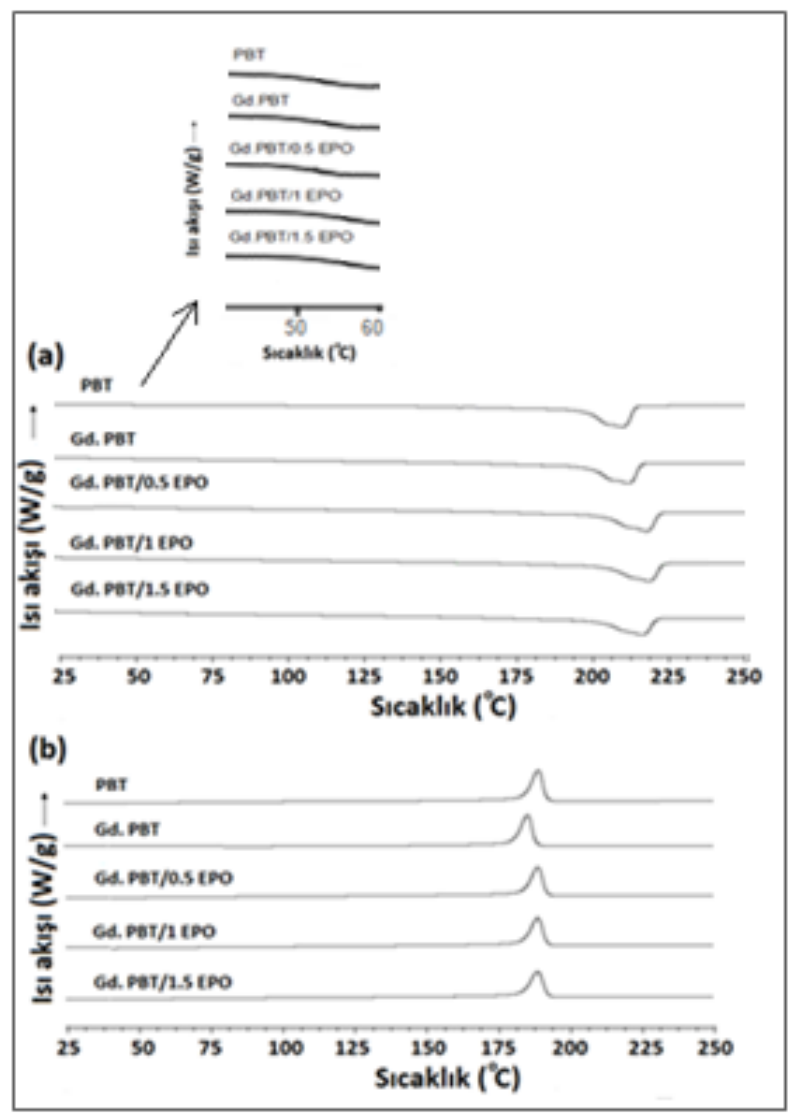

Şekil 5. Örneklerin DSC termogramları (a) 1sıtma, (b) soğutma basamakları

Tablo 3 ve Şekil 6' dan TGA sonuçları incelendiğinde, Gd. PBT’nin termal bozunma sıcaklığının örnekler içerisindeki en düşük değeri $\left(412{ }^{\circ} \mathrm{C}\right)$ gösterdiği gözlemlenmektedir. Bu sonuç daha önceki reolojik ve mekanik test sonuçlarını destekleyerek ekstrüderde termo-mekanik etkiler nedeniyle polimerin bozunmaya uğradığının bir göstergesidir. Diğer taraftan zincir uzatıcı içeren örneklerin polimer zincirlerinin yeniden bağlanmasıyla termal dayanımının geliştiği ve $T_{d}$ değerlerinin zincir uzatıcı konsantrasyonu ile arttığı gözlemlenmiştir. 

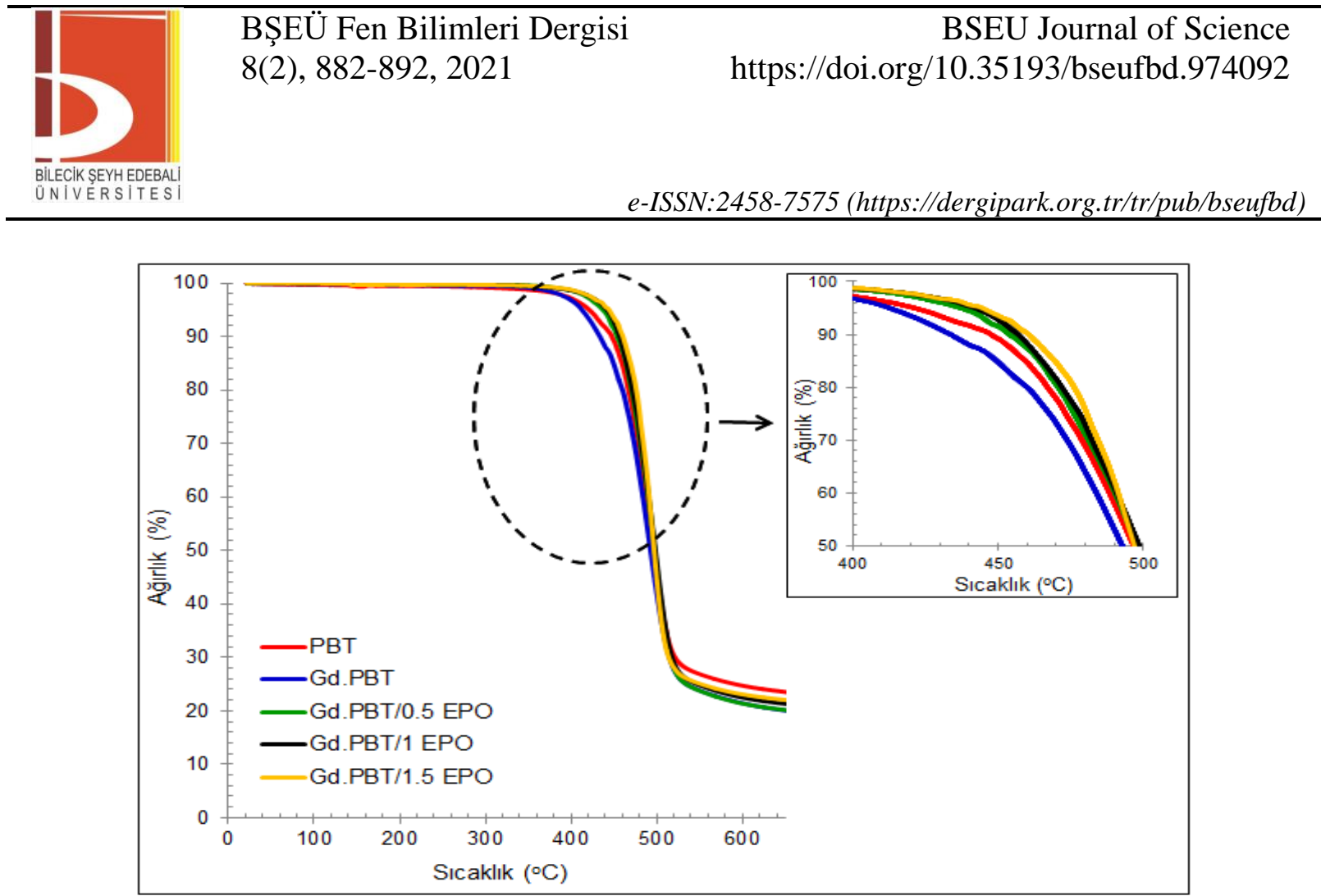

Şekil 6. Örneklerin TGA test sonuçları

\section{SONUÇLAR}

Bu çalışmada farklı konsantrasyon oranlarındaki polimerik bir zincir uzatıcının Gd. PBT'nin özelliklerine etkisi araştırılmıştır. PBT’nin mekanik geri dönüşümü sırasında ekstrüderde işlenirken termal bozunmaya uğradığ1, polimer zincirlerinin koparak molekül ağırlığı ve özelliklerinde önemli düşüşlerin yaşandığ gözlemlenmiştir. Buna çözüm olarak Gd. PBT’nin karboksil zincir sonu grupları ile polimerik esaslı zincir uzatıcının epoksi gruplarının ekstrüzyon sırasında reaksiyona girmeleri sağlanmıştır. Reolojik sonuçlar zincir uzatıcı içeren örneklerin viskoelastik özelliklerinde artışlar olduğunu ve bunun zincir uzatıcı konsantrasyonu ile doğru orantılı olarak değiştiğini göstermiştir. Bu verileri mekanik test sonuçları da destekleyerek zincir uzatılmış örneklerin elastik modül ve çekme dayanımı değerlerinde belirgin artışlar olmuştur. En yüksek zincir uzatıcı konsantrasyonu (\% ağ. 1.5) içeren örneğin Gd. PBT' ye göre elastik modülünde \% 33, çekme geriliminde ise \% 26 oranındaki yükseliş bunun bir göstergesidir. Örnekler artan molekül ağırlığı ve zincir dallanmalarına bağlı olarak daha zor kristallenme göstermiş, buna bağlı olarak toplam kristal yüzdesi azalarak kristallenme sıcaklıkları yükselmiştir. Bu etki özellikle zincir uzatıcı konsantrasyonundaki artış ile daha belirgin olmuş ve $\%$ ağ. 1.5 oranında zincir uzatıcı içeren örnek ile karşılaştırıldığında, Gd. PBT’nin toplam kristal yüzdesi \% 40’tan \% 27 oranına düşmüştür. TGA verileri zincir uzatıcının Gd. PBT’nin termal dayanımını geliştirerek, örneklerin termal bozunma sıcaklıklarını arttırdığını göstermiştir.

\section{KAYNAKLAR}

[1] D'Ambrieres, W. (2019). Plastics Recycling Worldwide: Current overview and desirable changes. Field Actions Science Reports, 19,12-21.

[2] Singh, N., Hui, D., Singh, R., Ahuja, I. P. S., Fea, L., \& Fraternali, F. (2017). Recycling of plastic solid waste: A state of art review and future applications. Composites Part B, 115, 409-422.

[3] Ragaert, K., Delva, L., \& Van Geem, K. (2017). Mechanical and chemical recycling of solid plastic waste. Waste Management, 6, 24-58.

[4] Quispe, N. B., Fernandes, E.G., Zanata, F., Bartoli, J. R., Souza, D. H. S., \& Ito, E. N. (2015). Organoclay nanocomposites of post-industrial waste poly (butylene terephthalate) from automotive parts. Waste Managementand Research, 33(10), 908-918.

[5] Knappich, F., Hartl, F., Schlummer, M., \& Maurer, A. (2017). Complete recycling of composite material comprising polybutylene terephthalate and copper. Recycling, 2(9), 1-12.

[6] Meng, C., \& Qu, J. (2018). Mechanical and thermal properties of poly (butylene terephthalate)/ethylene-vinyl acetate blends using vane extruder. e-Polymers,18(1), 67-73. 
[7] Da Silva, A. M. G., Barcelos, K. A., Da Silva, M. C., \& Morelli, C. L. (2020). Blend of recycled poly (ethylene terephthalate) and polycarbonate with polyaniline for antistatic packaging. Polymers and Polymer Composites, 28(5), 331-337.

[8] Martinez, A. L. C., Barrera, G. M., Diaz, C. E. B., Cordoba, L. I. A., Nunez, F. U., \& Hernandez, D. J. D. (2019). Recycled polycarbonate from electronic waste and its use in concrete: Effect of irradiation. Construction and Building Materials, 201,778-785.

[9] Buccella, M., Dorigato, A., Pasqualini, E., Caldara, M., \& Fambri, L. (2014). Chain extension behavior and thermo-mechanical properties of polyamide 6 chemically modified with 1,1-carbonyl-bis-caprolactam. Polymer Engineering and Science, 54(1), 158-165.

[10] Passalacqua, V., Pilati, F., Zamboni, V., Fortunato, B., \& Manaresi, P. (1976). Thermal degradation of poly(butylene terephthalate). Polymer, 17, 1044-1048.

[11] Tuna, B., \& Benkreira, H. (2019). Reactive extrusion of polyamide 6 using a novel chain extender. Polymer Engineering and Science, 59(S2), 25-31.

[12] Awaja, F., \& Pavel, D. (2005). Recycling of PET. European Polymer Journal, 41(7), 1453-1477.

[13] Villalobos, M., Awojulu, A., Greeley, T., Turco, G., \& Deeter, G. (2006). Oligomeric chain extenders for economic reprocessing and recycling of condensation plastics. Energy, 31(15), 3227-3234.

[14] Daver, F., Gupta, R.A., \& Kosior, E.N. (2008). Rheological characterisation of recycled poly(ethylene terephthalate) modified by reactive extrusion. Journal of Materials Processing Technology,204, 397-402.

[15] Makkam, S., \& Harnnarongchai, W. (2014). Rheological and mechanical properties of recycled PET modified by reactive extrusion. Energy Procedia, 56, 547-553.

[16] Snowdon, M. R., Abdelwahab, M., Mohanty, A. K., \& Misra, M. (2020). Mechanical optimization of virgin and recycled poly(ethylene terephthalate) biocomposites with sustainable biocarbon through a factorial design. Results in Materials, 5, 1-10.

[17] Zhao, Z., Wu, Y., Wang, K., Xia, Y., Gao, H., Luo, K., Cao, Z., \& Qi, J. (2020). Effect of the trifunctional chain extender on intrinsic viscosity, crystallization behavior, and mechanical properties of poly(ethylene terephthalate). ACS Omega, 5(30), 19247-19254.

[18] Xiao, L., Wang, H., Qian, Q., Jiang, X., Liu, X., Huang, B., \& Chen, Q. (2012). Molecular and structural analysis of epoxide-modified recycled poly(ethylene terephthalate) from rheological data. Polymer Engineering and Science, 52(10), 2127-2133.

[19] Tavares, A. A., Silva, D. F. A., Lima, P. S., Andrade, D. L. A. C. S., Silva, S. M. L., \& Canedo, E. L. (2016). Chain extension of virgin and recycled polyethylene terephthalate. Polymer Testing, 50, 26-32.

[20] Haralabakopoulos, A. A., Tsiourvas, D., \& Paleos, C. M. (1998). Chain extension of poly(ethylene terephthalate) by reactive blending using diepoxides. Journal of Applied Polymer Science, 71(13), 21212127.

[21] Incarnato, L., Scarfato, P., Maio, L. D., \& Acierno, D. (2000). Structure and rheology of recycled PET modified by reactive extrusion. Polymer, 41(18), 6825-6831.

[22] Awaja, F., Daver, F., \& Kosior, E. N. (2004). Recycled poly(ethylene terephthalate) chain extension by a reactive extrusion process. Polymer Engineering and Science, 44(8), 1579-1587.

[23] Daver, F., Gupta, R. A., \& Kosior, E. N. (2008). Rheological characterisation of recycled poly(ethylene terephthalate) modified by reactive extrusion. Journal of Materials Processing Technology, 204, 397-402.

[24] Tuna, B., \& Ozkoc, G. (2017). Effects of diisocyanate and polymeric epoxidized chain extenders on the properties of recycled poly (lactic acid). Journal of Polymers and the Environment, 25(4), 983-993.

[25] Beltran, F. R., Infante, C., Orden, M. U., \& Urreaga, J. M. (2019). Mechanical recycling of poly(lactic acid): Evaluation of a chain extender and a peroxide as additives for upgrading the recycled plastic. Journal of Cleaner Production, 219, 46-56.

[26] Casate de Andrade, M. F., Fonseca, G., Morales, A. R., \& Mei, L. H. I. (2018). Mechanical recycling simulation of polylactide using a chain extender. Advanced Polymer Technology, 37, 2053-2060.

[27] Standau, T., Hadelt, B., Schreier, P., \& Altstadt, V. (2018). Development of a bead foam from an engineering polymer with addition of chain extender: Expanded polybutylene terephthalate. Industrial \& Engineering Chemistry Research, 57(50), 17170-17176.

[28] Nofar, M., \& Oğuz, H. (2019). Development of PBT/recycled PET blends and the influence of using chain extender. Journal of Polymers and the Environment, 27, 1404-1417.

[29] Raffa, P., Coltelli, M. B., \& Castelvetro, V. (2014). Expanding the application field of post-consumer poly(ethylene terephthalate) through structural modification by reactive blending. Journal of Applied Polymer Science, 131(19), 1-11. 
[30] Japon, S., Boogh, L., Leterrier, Y., \& Manson, J. A. E. (2000). Reactive processing of poly(ethylene terephthalate) modified with multifunctional epoxy-based additives. Polymer, 41(15), 5809-5818.

[31] Nguyen, Q. T., Japon, S., Luciani, A., Leterrier, Y., \& Manson, J. A. E. (2001). Molecular characterization and rheological properties of modified poly(ethylene terephthalate) obtained by reactive extrusion. Polymer Engineering and Science, 41(8), 1299-1309.

[32] Corre, Y. M., Duchet, J., Reignier, J., \& Maazouz, A. (2011). Melt strengthening of poly(lactic acid) through reactive extrusion with epoxy-functionalized chains. Rheologica Acta, 50, 613-629.

[33] Al-Itry, R., Lamnawar, K., \& Maazouz, A. (2012). Improvement of thermal stability, rheological and mechanical properties of PLA, PBAT and their blends by reactive extrusion with functionalized epoxy. Polymer Degradation and Stability, 97, 1898-1914.

[34] Tuna, B., \& Benkreira, H. (2019). Chain extension of polyamide 6/organoclay nanocomposites. Polymer Engineering and Science, 59(6), 1233-1241.

[35] Samperi, F., Puglisi, C., Alicata, R., \& Montaudo, G. (2004). Thermal degradation of poly(butylene terephthalate) at the processing temperature. Polymer Degradation and Stability, 83, 11-17.

[36] Khankrua, R., Pivsa-Art, S., Hiroyuki, H., \& Suttiruengwong, S. (2014). Effect of chain extenders on thermal and mechanical properties of poly(lactic acid) at high processing temperatures: Potential application in PLA/Polyamide 6 blend. Polymer Degradation and Stability, 108, 232-240.

[37] Li, H., \& Huneault, M. A. (2011). Effect of chain extension on the properties of PLA/TPS blends. Journal of Applied Polymer Science, 122(1), 134-141.

[38] Tuna, B., \& Benkreira, H. (2018). Chain extension of recycled PA6. Polymer Engineering and Science, 58(7), 1037-1042. 